\title{
The importance of artificial drains for macroinvertebrate biodiversity in reclaimed agricultural landscapes
}

\author{
Kieran J. Gething $(\mathbb{D} \cdot$ Sally Little
}

Received: 17 December 2019/Revised: 30 May 2020/Accepted: 5 June 2020/Published online: 12 June 2020

(C) The Author(s) 2020

\begin{abstract}
Artificial drainage networks, ubiquitous within lowland agricultural landscapes in Europe and North America, exhibit a range of physical and chemical conditions, and may provide important habitat for aquatic organisms. Drains share hydromorphological characteristics with both lotic rivers and lentic ditches, potentially providing opportunities for a diverse range of taxa. However, little is known about the communities they support. A 23-year benthic macroinvertebrate dataset from four English catchments was used to determine the contributions of drains to biodiversity in a reclaimed agricultural landscape through a comparison of catchments, drain and river channels. A lack of significant differences in gamma diversity and high compositional overlap between rivers and drains showed that drains were not depauperate, and consistently contributed a
\end{abstract}

Handling editor: Verónica Ferreira

Electronic supplementary material The online version of this article (https://doi.org/10.1007/s10750-020-04325-8) contains supplementary material, which is available to authorized users.

K. J. Gething $(\bowtie) \cdot S$. Little

School of Animal, Rural and Environmental Sciences, Nottingham Trent University, Southwell NG25 0QF, UK e-mail: kieran.gething2015@my.ntu.ac.uk

K. J. Gething

School of Science and Technology, Nottingham Trent

University, Nottingham NG11 8NS, UK richness comparable to that of rivers. High-compositional overlap suggested that drains from different catchments contributed comparably to aquatic biodiversity at the landscape scale. Significant differences in environmental conditions (inferred from biotic indices) between catchments may have marginally increased landscape gamma diversity through turnover. Despite similarities in community composition, non-native species were less abundant in drains. This study demonstrates the importance of drains for habitat provision in intensively farmed catchments, and highlights the need for focused research into their management and conservation potential.

Keywords Artificial waterbody · Drainage channel · Benthic macroinvertebrates - Species richness . Community composition · Drainage networks

\section{Introduction}

Anthropogenic pressures operating on a global scale are expected to cause a continued decline in freshwater biodiversity over the coming decades (Johnson et al., 2017; Reid et al., 2019). Such a reduction in biodiversity would be detrimental to the sustained health of freshwater resources, as diversity is widely accepted to improve resilience to environmental pressures (both anthropogenic and natural) and aid in 
the provision of tangible ecosystem services, including carbon and nutrient cycling and organic matter breakdown (Giller et al., 2004; Dudgeon, 2010; Brooks et al., 2016). The sustained loss of freshwater biodiversity over the past century is attributable to a number of factors (e.g. changing climatic trends and increased anthropogenic pollution), however, habitat loss and modification are thought to have some of the most significant and far reaching consequences (Reid et al., 2019). In Europe and North America the drainage and reclamation of low-lying marsh and fenland areas for agriculture means that artificial drainage networks are ubiquitous components of the landscape (Hill et al., 2016). In the UK, land drainage and reclamation (which has been facilitated through construction of these networks) has reduced some fenlands to one percent of their original area (South Lincolnshire Fenlands Partnership, 2019). This, combined with the continued management of the channels to prevent flooding and maintain water resources for agriculture, has intensified pressures upon formerly biodiverse fenland areas, with artificial channels now constituting some of the only remaining viable habitat for formerly abundant and widespread aquatic species (Manhoudt \& Snoo, 2003; Verdonschot et al., 2011; Dollinger et al., 2015). The importance and contribution of these artificial channels in supporting aquatic biodiversity has, however, been understudied (Hill et al., 2016).

Agricultural drainage networks are typically comprised of a parent river channel, from which artificial channels known as ditches and drains have been constructed to facilitate irrigation and/or land drainage. Ditches are defined as artificial, linear channels $<3 \mathrm{~m}$ wide which follow anthropogenic boundaries (e.g. field margins) (Williams et al., 2003). Drains are larger features ( $>5 \mathrm{~m}$ wide) which display otherwise similar characteristics (Clarke, 2015; Hill et al., 2016). Despite this distinction, the size threshold between large ditches and small drains remains unclear and has resulted in the frequent citing of 'ditches' to refer to all artificial channels within such networks (e.g. Shaw et al., 2015-with features 0.9-11 m wide classified as ditches). Within drainage networks, ditches have been shown to display lower benthic macroinvertebrate diversity relative to their parent rivers (Williams et al., 2003; Davies et al., 2008), with ditch communities sharing more biotic compositional similarities with lentic, rather than lotic systems (Verdonschot et al., 2011, 2012). As such, ditches have been shown to act as a refuge for some formerly widespread lentic fenland species in intensified agricultural landscapes (Clarke, 2015; Shaw et al., 2015), particularly Coleoptera taxa of conservation interest (Davies et al., 2008; Shaw et al., 2015; Rolke et al., 2018).

Drains exist along a continuum between ditches and rivers, and share environmental characteristics with both channel types. Like ditches, drains are typically slow flowing, trapezoidal in profile and intensively managed to maintain drainage capacity (i.e. through vegetation management; Mayer et al., 2017). Like their parent rivers, drains are wider and deeper than ditches, bounded by high banks and contain water allyear round (Buisson et al., 2008). Drains may, therefore, support high levels of benthic macroinvertebrate diversity (potentially on a scale comparable with their parent rivers), in addition to rarer species of conservation interest which are found in ditches (Hill et al., 2016). Thus, drains may provide some of the only remaining freshwater habitat in agricultural landscapes, and have the potential to enhance aquatic macroinvertebrate biodiversity through their contribution to landscape gamma diversity. Whilst the benthic macroinvertebrate communities of ditches and rivers within these networks have been partially characterised (e.g. Williams et al., 2003; Davies et al., 2008), drain communities remain poorly defined, with little research undertaken on their importance for aquatic biodiversity and potential to support species of conservation interest (but see Hill et al., 2016). The Lincolnshire and Cambridgeshire Fenlands (the Fens) are areas of formerly biodiverse marshland which now consist of nationally important agricultural land, maintained by networks of ditches, drains and rivers (Skempton, 1998; South Lincolnshire Fenlands Partnership, 2019). Owing to their importance for both irrigation and flood risk mitigation, artificial drainage channels are ubiquitous within the fenland landscape, however, the biodiversity and the overall environmental quality of the drainage networks is, for the most part, undocumented (Hill et al., 2016). This study aims to determine the contributions of drains to benthic macroinvertebrate biodiversity in this agricultural fenland landscape through a comparison of catchments and drain and river channels. This research is important as drains face intense pressures via the accumulation of 
pollutants from smaller ditches (Sánchez-Bayo et al., 2011; Silva et al., 2015), and management activities by a range of stakeholders (Environment Agency, 2006; Thaler and Levin-Keitel, 2016). The extent to which these activities influence macroinvertebrate communities are, however, difficult to quantify due to the high density of artificial channels within drainage networks and the infrequency of biological monitoring undertaken (Hill et al., 2016). A better understanding of drain communities, which are currently poorly defined on the ditch to river continuum, will allow steps toward the implementation of successful management strategies to support biodiversity in anthropogenically altered landscapes.

\section{Methods}

Study area and site selection

Four river catchments (the Steeping, Witham, Welland and Nene) were selected across the Lincolnshire and Cambridge Fenlands in the East of England (Fig. 1), all of which contain a parent river, extensive artificial drainage networks (drains and ditches) and long-term macroinvertebrate data records. For the purposes of this study, drains were defined by the description of ditches given by Williams et al., (2003) with the additional stipulations of being $\geq 4 \mathrm{~m}$ in width at bank-full discharge and continuously wetted (see Online Resource 1). In the selected catchments, all drains were $>40$ years old and managed in a similar manner to rivers, with annual vegetation control, periodic dredging and embankment. The catchments of the River Steeping (length: $45 \mathrm{~km}$, catchment area: $170 \mathrm{~km}^{2}$ ), R. Witham (length: $132 \mathrm{~km}$, catchment area: $3817 \mathrm{~km}^{2}$ ), R. Welland (length: $105 \mathrm{~km}$, catchment area: $1580 \mathrm{~km}^{2}$ ) and R. Nene (length: $160 \mathrm{~km}$, catchment area: $1630 \mathrm{~km}^{2}$ ) all flow through the area known as 'The Fens' prior to discharging into the North Sea via The Wash. The Fens are underlain by Jurassic mud, silt and sandstone with a diverse surface geology of fluvial and marine deposits (Gibbard et al., 2018).

Macroinvertebrate sample collection and processing

Long-term benthic macroinvertebrate records were obtained from the Environment Agency (EA), the statutory monitoring body for England. The dataset consisted of 73 samples collected between 1990 and 2013 from 13 channels in the Steeping $(n=10)$, Witham $(n=24)$, Welland $(n=24)$ and Nene $(n=15)$ catchments. Within each catchment, sampling was undertaken at the same site on each channel, with all samples being collected at comparable intervals (Fig. 1 and Online Resource 2). Sampling
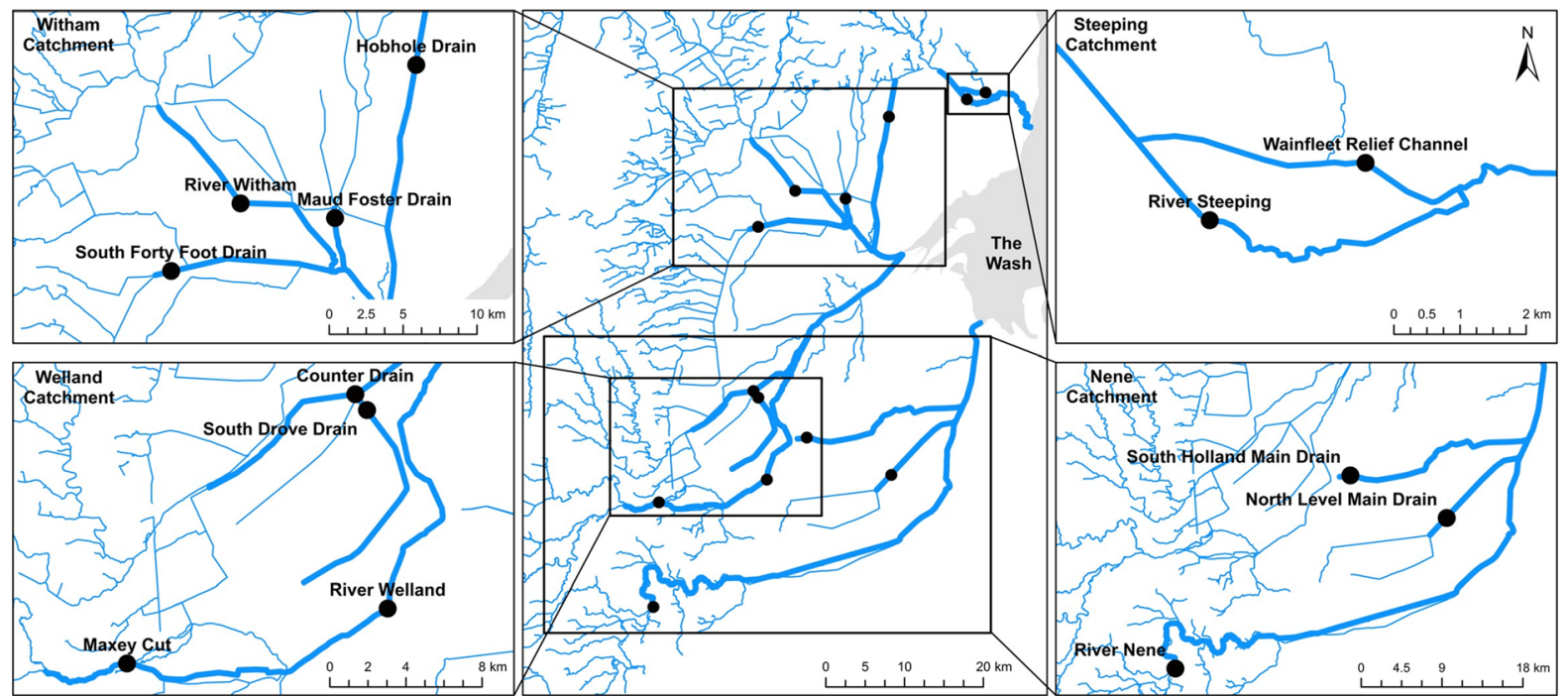

Fig. 1 Waterbodies located in southern Lincolnshire/Cambridgeshire Fens with the reaches under investigation shown in bold and sampling locations marked as circles 
was undertaken via three minutes of active kick sampling in accordance with the EA's BT001 method in the marginal area of the channel (see Murray-Bligh, 1999). Macroinvertebrate family groups were used during statistical analyses to avoid the artificial inflation of richness with the mixed level of identification in the original dataset.

Methods of data analysis

All diversity and statistical analyses were undertaken in R Studio, with some operations utilising the Vegan package in $\mathrm{R}$ language for environment and statistical computing v.3.5.1 (Oksanen et al., 2019; R Core Team, 2018). To characterise rivers and drains at the catchment scale, the number of families present at each site (all samples from a site pooled-alpha diversity), and within each catchment (all samples collected within the catchment pooled-catchment gamma diversity) was calculated via the "specnumber" function. At the landscape scale (all four catchments), calculations of family richness were conducted for pooled river samples (river gamma diversity), pooled drain samples (drain gamma diversity) and all samples (landscape gamma diversity). Differences between river and drain communities, and the contribution of the four catchments to landscape gamma diversity (landscape beta diversity) were calculated as beta diversity and its component parts (number of unique taxa and nestedness) via the "betapart.core" and "beta.multi" functions from the betapart R package using default options (Baselga and Orme, 2012; Baselga et al., 2018).

A Shapiro-Wilks normality test followed by a oneway analysis of variance (ANOVA) was used to test for significant differences in catchment gamma diversity between catchments, and between river and drain gamma diversity. To highlight compositional differences between rivers and drains from all catchments (all samples grouped by channel type: river or drain), analysis of similarity (ANOSIM) and similarity of percentages (SIMPER) were undertaken. Within ANOSIM and SIMPER, family abundance data were square root transformed. Summaries of ANOSIM were produced via Principle Components Analysis (PCA) as a preliminary Detrended Correspondence Analysis indicated an axis 1 length $<3$ standard units. All samples were plotted, however, owing to the large number of families recorded (72), only the most influential highlighted by SIMPER were selected for the generation of a biplot.

In the absence of a record of environmental conditions, the Biological Monitoring Working Party Average Score Per Taxon (BMWP-ASPT; Armitage et al., 1983; Hawkes, 1998), Lotic-invertebrate Index for Flow Evaluation (LIFE; Extence et al., 1999) and Proportion of Sediment-sensitive Invertebrates (PSI; Extence et al., 2013) scores were calculated to explore potential factors influencing differences between drain and river communities. These indices, indicative of organic pollution, flow conditions and fine sediment pollution respectively, were chosen as they reflect environmental issues which may be expected in agricultural drainage channels. A Shapiro-Wilks normality test and Kruskal-Wallis $H$ test was applied to all calculated indices in order to highlight any significant differences between catchments, and between rivers and drains. When significant differences were detected, a Mann-Whitney $U$ test was applied to establish the nature of the variance.

\section{Results}

Over the sampling period, a total of 25,867 individuals were recorded from 72 families (landscape gamma diversity). Drains ( $n=51$ ) supported 15,961 individuals from 70 families (drain gamma diversity), whilst rivers $(n=22)$ supported 9906 individuals from 56 families (river gamma diversity). The five most abundant taxa, two of which were non-native species (Crangonyx pseudogracilis (Bousfield, 1958) and Potamopyrgus antipodarum (Grey, 1843)), all displayed abundances $>1400$ individuals. Crangonyx pseudogracilis was the most abundant species within the dataset, with 2124 individuals observed, followed by Asellus aquaticus (Linnaeus, 1758) (1989 individuals), Oligochaetes (1872 individuals), P. antipodarum (1495 individuals) and Cloeon dipterum (Linnaeus, 1761) (1440 individuals). No species of conservation interest were recorded in the rivers or drains. Drains did, however, harbour lower abundances of non-native species (C. pseudogracilis, Dreissena polymorpha (Pallas, 1771) and P. antipodarum), comprising $10.5 \%$ of the sample abundance compared to $15.2 \%$ in rivers. 
Catchment contribution to landscape scale diversity

Alpha diversity varied between rivers and drains in the four catchments, with the 13 channels containing between 30 and 46 taxa. Catchment gamma diversity ranged from 41 to 60 taxa, with the Welland catchment recording the highest diversity and the Steeping catchment recording the lowest (Table 1). However no significant difference in gamma diversity was recorded between catchments $(F(3)=0.008$, $P=0.938)$. Landscape beta diversity was 0.328 (Sørensen, Nest: 0.122, Turn: 0.206), highlighting broad similarities, but some differences in catchment community composition. The lowest compositional overlap of 35 taxa occurred between the Steeping and the Nene catchments. Despite this, the two catchments were still highly nested, with $68.6 \%$ of taxa found in the Nene catchment also present in the Steeping.

Rivers and drains at the landscape scale

With gamma diversities of 56 and 70 families respectively, rivers and drains contributed 2 and 16 unique taxa to landscape gamma diversity, although these differences are likely an artefact of the greater number of drain samples in the dataset and may be affected by the level of taxonomic identification used. No significant difference was recorded between river and drain gamma diversity $(F(1)=0.003, P=0.955)$. The overall compositional overlap between rivers and drains was $96.4 \%$. This is reflected in a lower beta diversity (0.145) than was observed between catchments. At this scale, nestedness was more important than turnover in driving dissimilarity (Nest: 0.109, Turn: 0.036).

This compositional similarity at the landscape scale is reflected in the PCA which generally showed a high degree of overlap between river and drain samples throughout the sampling period (Fig. 2). Three samples were outliers to this trend (i,e, Counter Drain (17/ 10/2003), River Welland (22/10/2007) and Hobhole Drain (05/04/2006) samples from 11/2003; Fig. 2), likely due to high abundances of a single taxon in these samples (i.e. Baetidae, C. pseudogracilis and Chironomidae respectively). ANOSIM recorded a significant difference between channel types $(P=0.002)$, however the low $R$-value $(R=0.153)$ indicated a high degree of overlap. SIMPER identified that the marginal dissimilarity between rivers and drains was likely due to a high abundance of Baetidae in drains (accounting for $6.01 \%$ of the variance) and the nonnative $C$. pseudogracilis (the only species recorded from the Crangonyctidae family) which occurred more frequently in rivers (accounting for a further $5.48 \%$ of the variation; also see Fig. 3). These results were not, however, statistically significant, likely reflecting the similar contributions to dissimilarity of multiple taxa (with the top 10 each contributing within $2 \%$ of the highest scoring family-Baetidae) and contrasting patterns in each individual catchment.
Table 1 Alpha diversity and catchment gamma diversity of rivers and drains (A)

\begin{tabular}{llll}
\hline Catchment & Channel & Alpha diversity & Catchment gamma diversity \\
\hline \multirow{2}{*}{ Steeping } & River Steeping & 33 & 41 \\
& Wainfleet Relief Channel (A) & 36 & 57 \\
Witham & River Witham & 41 & \\
& Maud Foster Drain (A) & 42 & \\
& South Forty Foot Drain (A) & 43 & 60 \\
\multirow{5}{*}{ Welland } & Hobhole Drain (A) & 37 & \\
& River Welland & 43 & \\
& Maxey Cut (A) & 46 & 52 \\
& South Drove Drain (A) & 44 & \\
\multirow{5}{*}{ Nene } & Counter Drain (A) & 46 & \\
& River Nene & 42 & \\
& North Level Main Drain (A) & 30 & \\
& South Holland Main Drain (A) & 32 & \\
& &
\end{tabular}




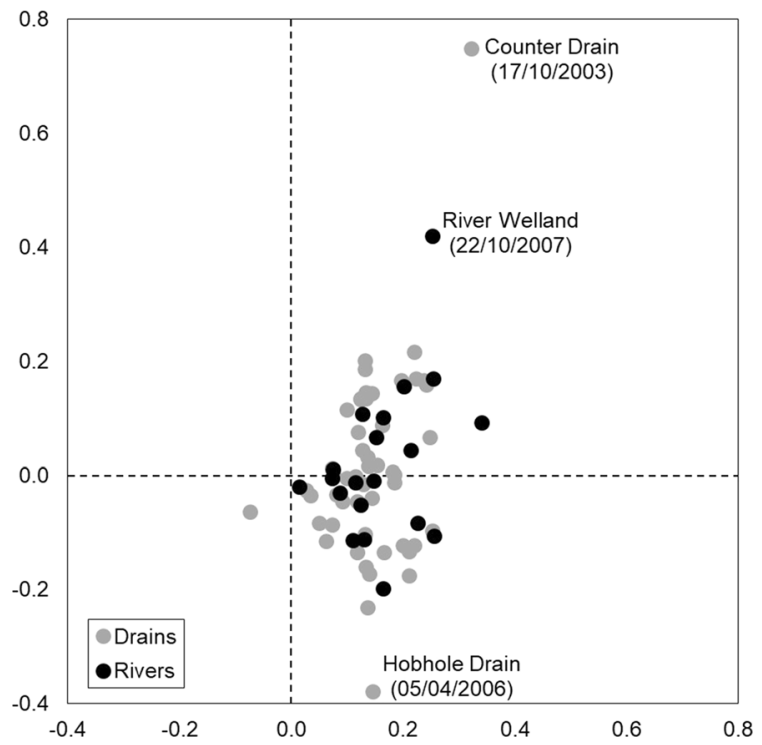

Fig. 2 PCA ordination of all samples collected from rivers (black) and drains (grey) between 1990 and 2013. Outliers to the general trend are labelled

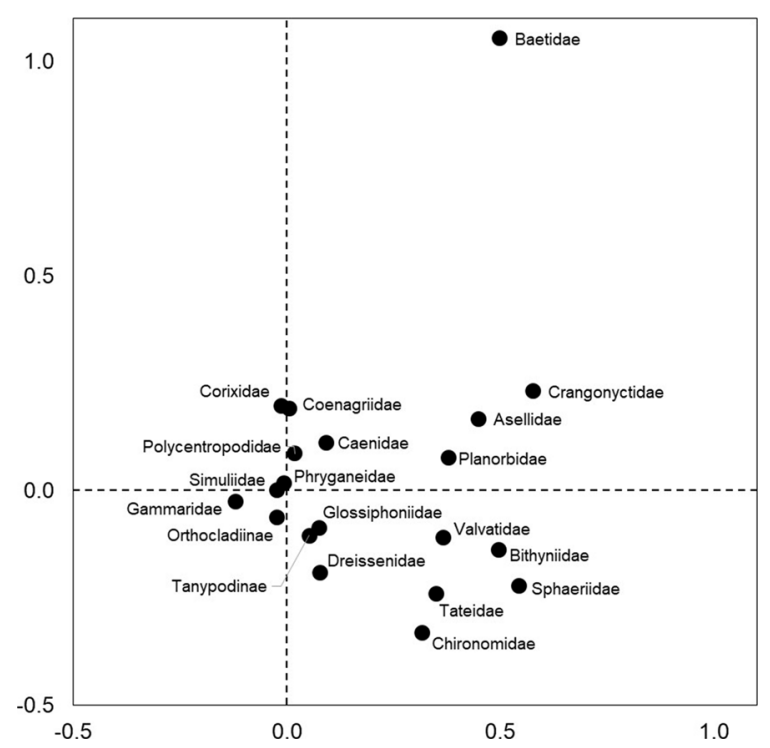

Fig. 3 PCA ordination of families responsible for the largest dissimilarity between river and drain communities as determined by SIMPER

Biotic indices in rivers and drains

Significant differences in BMWP-ASPT $(H(3)=16.117, P=0.001)$, LIFE $(H(3)=18.304$, $P \leq 0.001)$ and PSI $(H(3)=13.165, P=0.003)$ were detected between catchments. The Welland catchment had some of the most variable BMWP-ASPT and PSI scores (Fig. 4), a factor likely contributing to its significant differences with every other catchment for BMWP-ASPT (Steeping: $U=23, \quad P=<0.001$; Witham: $U=124, \quad P=0.002$; Nene: $U=261$, $P=0.021)$ and the Witham and Nene for PSI ( $U=120, P=0.002$ and $U=111, P=0.046$, respectively). The Nene catchment had some of the highest LIFE scores recorded in this study, contributing to significant differences with all other catchments (Steeping: $U=28, P=0.010$; Witham: $U=57$, $P=0.001$; Welland: $U=131, P=0.003)$. At the landscape scale, both rivers and drains recorded PSI scores indicative of sedimented (PSI 20-40) and

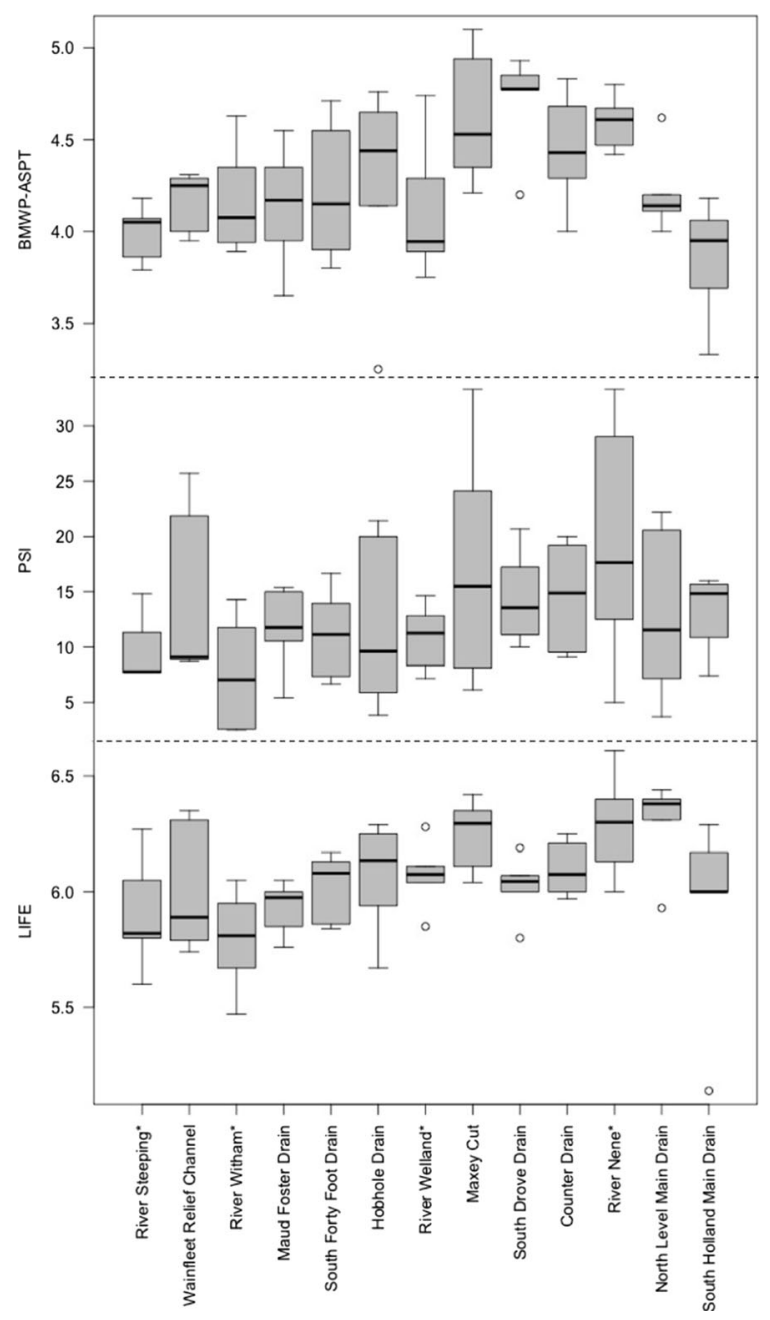

Fig. 4 Box and whisker plots displaying BMWP-ASPT, PSI and LIFE of samples collected in rivers (marked with a *) and drains between 1990 to 2013 
heavily sedimented (PSI <20) habitats, low LIFE scores and BMWP-ASPT scores below the national mean of 5.14 (Fig. 4). However, no statistically significant differences in BMWP-ASPT $(H(1)=0.061, \quad P=0.805), \quad$ LIFE $\quad(H(1)=0.030$, $P=0.862)$ or PSI $(H(1)=0.105, P=0.746)$ were detected between rivers and drains.

\section{Discussion}

Artificial drainage systems are a fundamental component of lowland agricultural landscapes, used to supply water for irrigation and mitigate flood risk (Buisson et al., 2008; Rogger et al., 2017). The high density of such networks and range of channel types they include may, however, also provide important habitat for a diverse range of aquatic species (Manhoudt \& Snoo, 2003; Dollinger et al., 2015; Biggs et al., 2017). Drains commonly share characteristics with both ditches and the parent river within the catchment, and thus may support diverse lotic type communities whilst simultaneously containing species known to frequent more lentic ditch habitats. To date, however, the ecological importance of such channels has remained largely unexplored (Hill et al., 2016). Therefore, this study specifically sought to assess the contribution of agricultural drains to macroinvertebrate biodiversity at the landscape scale.

The lack of significant differences in gamma diversity and high degree of compositional overlap between rivers and drains (reflected in low beta diversity) highlight that drains are not depauperate, and contribute a richness comparable to that of rivers to landscape gamma diversity. This observation supports the conclusions of Hill et al. (2016), that agricultural drains make a significant contribution to the provision of habitat for aquatic macroinvertebrates in the Lincolnshire and Cambridgeshire fens. A lack of significant differences in catchment gamma diversity and low landscape beta diversity highlighted a consistent contribution to richness across the four catchments. This finding is of greater importance when considered in association with the decline of traditional fenland habitats and the prevalence of drains within the study area (South Lincolnshire Fenlands Partnership, 2019), and implies that larger artificial channels may contribute to biodiversity consistently across the Lincolnshire Fens. It should be noted, however, that the level of taxonomic level of identification used (family) may mask some differences between rivers and drains. However, the effects of this is likely limited due to the close proximity and high connectivity between drains and their parent rivers (Online Resource 1c), factors which have previously been demonstrated to foster faunal similarity (Gallardo et al., 2008).

As expected in intensively managed agricultural catchments, environmental pressures (inferred from biotic indices) such as reduced water quality, due in part to organic pollution, high sedimentation and low flows were greater in the drainage network channels of this study than those in lowland stream reference sites (Clarke \& Davy-Bowker, 2014; Extence et al. 1999; 2013). Despite this, the channels were taxa rich, supporting a higher number of families than the mean reported from the reference sites (32; Clarke \& DavyBowker, 2014). Significant differences in environmental conditions (based on our indices) were recorded between catchments. This variation is notable as Armitage et al. (2003) found that variability in physical and chemical conditions between rivers and ditches led to increased floodplain biodiversity and increased abundances of sensitive taxa. No significant differences in richness were detected between catchments in the Fens, however, beta diversity (particularly the turnover component) between catchments was higher than overall beta diversity between rivers and drains. Although further investigation would be required to confirm this, it implies that Armitage et al.'s (2003) findings are applicable at larger spatial scales as differences in environmental conditions between catchments may have increased landscape gamma diversity through turnover, despite each individual catchment supporting an overall similar number of taxa.

Although small inter-catchment differences in community composition were observed, the high degree of compositional overlap and lack of significant differences in environmental conditions (inferred from biotic indices) between rivers and drains implies a relatively uniform range of habitat conditions at the landscape scale. This, in conjunction with the high connectivity and lack of physical barriers within the study area, may explain the structural similarities observed between communities in the two channel types (Gallardo et al., 2008). In addition, drains have been constructed within the study area over the last $c .400$ years (Black Sluice 
Internal Drainage Board, 2019), thus removing one of the barriers to high diversity suggested by Clifford et al. (2018) that artificial water bodies have a limited ecological history.

No species of conservation interest were recorded in this study, however these may have been missed by the mixed level of taxonomic identification applied to the original dataset. When conducting investigations on South Drove Drain and North Drove Drain in the Welland catchment, Hill et al. (2016) found two species of conservation concern (Oulimnius major and Scarodytes halensis), albeit in low abundances. This finding suggests that such taxa are present in drains within the immediate study area, further highlighting the potential importance of drains within the landscape, and the need for further investigation to assess the full conservation potential of these channels.

Drains across all four catchments appeared to act as a refuge from non-native species. Notably, C. pseudogracilis was more common in rivers (particularly the Witham and Nene), despite their high connectivity with drains. Crangonyx pseudogracilis do not have the negative community wide effects of other non-native species (e.g. Dikerogammarus villosus (Sowinsky, 1894)), however, they are highly successful resource competitors (Great Britain Non-Native Species Secretariat, 2013). As C. pseudogracilis is tolerant of more polluted sites than native amphipods (Dick et al., 1999; MacNeil et al., 2000), their increased abundance in rivers may reflect a marginally degraded habitat provision relative to drains, and highlights the potential importance of drains as refugia from competition with non-native species. However, any habitat degradation as a result of pollution is likely to be marginal due to the lack of significant differences in water quality (inferred from biotic indices) between drains and rivers recorded in this study. Degradation due to differences in channel management is also unlikely, as despite the management of agricultural channels being typically undertaken at the catchment and sub-catchment scale (e.g. activities discussed by Needelman et al., 2007; Buisson et al., 2008), the size and intended function of all rivers and drains within this study elicit similar management from the Environment Agency or an Internal Drainage Board authority.

Since the year 2000, waterbodies in the UK have been managed under the European Union's Water Framework Directive (WFD: 2000/60/EC). Drains are designated as Artificial Water Bodies (AWB), therefore, there is no obligation for them to achieve the WFD requirement of good ecological status (GES), rather a target of good ecological potential (GEP: Borja \& Elliott, 2007). Increased pressure on regulatory agencies to achieve GES means that these channels often become neglected during routine biological monitoring programmes, potentially putting their diverse communities at risk (Hill et al., 2016). As AWB's, drains are primarily managed for their utility rather than their ecology. Despite this, drains were compositionally similar to their parent rivers and contributed comparably to aquatic biodiversity at the landscape scale. This highlights the importance of these channels and the potential to enhance this biodiversity through more ecologically considerate management. Good Ecological Potential is achieved through the implementation of mitigation measures which improve the ecology of channels whilst not impacting on their primary function (Kampa \& Hansen, 2004; Mayer et al., 2017). In drains, these may include improving the ecological value of marginal aquatic habitat, banks and riparian zones and increasing the connectivity between these, the regulated management of marginal and channel vegetation and sediment, management of water level and flow and informing landowners on sensitive management practices (Buisson et al., 2008; Mayer et al., 2017). The Fenlands contain $6100 \mathrm{~km}$ of drainage watercourses managed by 34 Internal Drainage Boards (Mayer et al., 2017). Therefore, applying appropriate mitigation measures to and ensuring the holistic co-ordinated management of the drains in this network may substantially enhance aquatic biodiversity at the landscape scale.

Acknowledgements The authors would like to thank the Environment Agency for allowing access to their data archives, and the anonymous reviewers for providing insightful comments which improved the manuscript.

Data availability The datasets analysed during this study were sourced from the Environment Agency for England and Wales via freedom of information requests sent to enquires@environment-agency.gov.uk. Figure 1 contains OS data (C) Crown copyright and database right 2018, free to use under Open Government Licence.

\section{Compliance with ethical standards}

Conflict of interest The authors declare that they have no conflict of interest. 
Open Access This article is licensed under a Creative Commons Attribution 4.0 International License, which permits use, sharing, adaptation, distribution and reproduction in any medium or format, as long as you give appropriate credit to the original author(s) and the source, provide a link to the Creative Commons licence, and indicate if changes were made. The images or other third party material in this article are included in the article's Creative Commons licence, unless indicated otherwise in a credit line to the material. If material is not included in the article's Creative Commons licence and your intended use is not permitted by statutory regulation or exceeds the permitted use, you will need to obtain permission directly from the copyright holder. To view a copy of this licence, visit http://creativecommons.org/licenses/by/4.0/.

\section{References}

Armitage, P. D., D. Moss, J. F. Wright \& M. T. Furse, 1983. The performance of a new biological water quality score system based on macroinvertebrates over a wide range of unpolluted running-water sites. Water Research 17: 333-347.

Armitage, P. D., K. Szoszkiewicz, J. H. Blackburn \& I. Nesbitt, 2003. Ditch communities: a major contributor to floodplain biodiversity. Aquatic Conservation: Marine and Freshwater Ecosystems 13: 165-185.

Baselga, A., C. D. L. Orme, S. Villeger, J. De Bortoli, \& F. Leprieur, 2018. Betapart: partitioning beta diversity into turnover and nestedness components. R package version 1.5.1.

Baselga, A. \& C. D. L. Orme, 2012. Betapart: an R package for the study of beta diversity. Methods in Ecology and Evolution 3(5): 808-812.

Biggs, J., S. von Frumetti \& M. Kelly-Quinn, 2017. The importance of small waterbodies for biodiversity and ecosystem services: implications for policy makers. Hydrobiologia 793: 3-39.

Black Sluice Internal Drainage Board, 2019. History I Black Sluice Internal Drainage Board. https://www. blacksluiceidb.gov.uk/about/history/.

Borja, A. \& M. Elliott, 2007. What does 'good ecological potential' mean, within the European Water Framework Directive? Marine Pollution Bulletin 54: 1559-1564.

Brooks, E. G. E., R. A. Holland, W. R. T. Darwall \& F. Eigenbrod, 2016. Global evidence of positive impacts of freshwater biodiversity on fishery yields. Global Ecology and Biogeography 25: 553-562.

Buisson, R. S. K., P. M. Wade, R. L. Cathcart, S. M. Hemmings, C. J. Manning \& L. Mayer, 2008. The drainage channel biodiversity manual: Integrating wildlife and flood risk management. Association of Drainage Authorities and Natural England, Peterborough.

Clarke, S. J., 2015. Conserving freshwater biodiversity: the value, status and management of high-quality ditch systems. Journal for Nature Conservation 24: 93-100.

Clarke, R. T., \& J. Davy-Bowker, 2014. River invertebrate classification tool science development project: modifications for WHPT and other abundance-weighted indices. Scottish Environment Protection Agency, Wareham, UK.

Clifford, C., J. Heffernan, C. C. Clifford \& J. B. Heffernan, 2018. Artificial aquatic ecosystems. Water 10: 1096.

Davies, B. R., J. Biggs, P. J. Williams, J. T. Lee \& S. Thompson, 2008. A comparison od the catchment sizes of rivers, streams, ponds, ditches and lakes: implications for protecting aquatic biodiversity in an agricultural landscape. Hydrobiologia 597: 7-17.

Dick, J. T. A., C. MacNeil \& R. Anderson, 1999. The distribution of Crangonyx pseudogracilis Bousfield, 1958 (Crustacia: Amphipoda) in Northern Ireland, with notes on its ecology and behaviour. The Irish Naturalists' Journal 26: 236-240.

Dollinger, J., C. Dagès, J.-S. Bailly, P. Lagacherie \& M. Voltz, 2015. Managing ditches for agroecological engineering of landscape: a review. Agronomy for Sustainable Development 35: 999-1020.

Dudgeon, D., 2010. Prospects for sustaining freshwater biodiversity in the 21 st century: linking ecosystem structure and function. Current Opinion in Environmental Sustainability 2: 422-430.

Environment Agency, 2006. Improving stakeholder engagement in flood risk management decision making and delivery. Environment Agency, Bristol: 47.

Extence, C. A., D. M. Balbi \& R. P. Chadd, 1999. River flow indexing using British benthic macroinvertebrates: a framework for setting hydroecological objectives. Regulated Rivers: Research \& Management 15: 545-574.

Extence, C. A., R. P. Chadd, J. England, M. J. Dunbar, P. J. Wood \& E. D. Taylor, 2013. The assessment of fine sediment accumulation in rivers using macro-invertebrate community response. River Research and Applications 29: 17-55.

Gallardo, B., M. García, Á. Cabezas, E. González, M. González, C. Ciancarelli \& F. A. Comín, 2008. Macroinvertebrate patterns along environmental gradients and hydrological connectivity within a regulated river-floodplain. Aquatic Sciences 70: 248-258.

Gibbard, P. L., R. G. West \& P. D. Hughes, 2018. Pleistocene glaciation of Fenland, England, and its implications for evolution of the region. Royal Society Open Science 5: 170736.

Giller, P. S., H. Hillebrand, U.-G. Berninger, M. O. Gessner, S. Hawkins, P. Inchausti, C. Inglis, H. Leslie, B. Malmqvist, M. T. Monaghan, P. J. Morin \& G. O’Mullan, 2004. Biodiversity effects on ecosystem functioning: emerging issues and their experimental test in aquatic environments. Oikos 104: 423-436.

Great Britain Non-Native Species Secretariat, 2013. Crangonyx pseudogracilis risk assessment.

Hawkes, H., 1998. Origin and development of the biological monitoring working party score system. Water Research 32: 964-968.

Hill, M. J., R. P. Chadd, N. Morris, J. D. Swaine \& P. J. Wood, 2016. Aquatic macroinvertebrate biodiversity associated with artificial agricultural drainage ditches. Hydrobiologia 776: 249-260.

Johnson, C. N., A. Balmford, B. W. Brook, J. C. Buettel, M. Galetti, L. Guangchun \& J. M. Wilmshurst, 2017. 
Biodiversity losses and conservation responses in the Anthropocene. Science 356: 270-275.

Kampa, E. \& W. Hansen, 2004. Definition of good ecological potential. In Kampa, E. \& W. Hansen (eds), Heavily modified waterbodies: Synthesis of 34 case studies in Europe. Springer, Berlin: 153-163.

MacNeil, C., J. T. A. Dick \& R. W. Elwood, 2000. Differential physico-chemical tolerances of amphipod species revealed by field transplantations. Oceologia 124: 1-7.

Manhoudt, A. G. E. \& G. R. de Snoo, 2003. A quantitative survey of semi-natural habitats on Dutch arable farms. Agriculture, Ecosystems and Environment 97: 235-240.

Mayer, L., I. Moodie, C. Carson, K. Vines, M. Nunns, K. Hall, M. Redding, P. Sharman, \& S. Bonney, 2017. Good ecological potential in Fenland waterbodies: A guide to management strategies and mitigation measures for achieving good ecological potential in Fenland waterbodies. Association of Drainage Authorities \& Environment Agency.

Murray-Bligh, J. A. D., 1999. BT001: Procedure for collecting and analysing macro-invertebrate samples. Quality management systems for environmental monitoring: biological techniques. Environment Agency, Bristol.

Needelman, B. A., P. J. A. Kleinman, J. S. Strock \& A. L. Allen, 2007. Improved management of agricultural drainage ditches for water quality protection: an overview. Journal of Soil and Water Conservation 62: 171-178.

Oksanen, J., F. Blanchet, M. Freindly, R. Kindt, P. Legendre, D. McGlinn, P. Minchin, R. O’Hara, G. Simpson, P. Solymos, M. Henry, H. Stevens, E. Szoecs, \& H. Wagner, 2019. Vegan - Community Ecology Package: Ordination, Diversity and Dissimilarities. R package version 2.5-6.

R Core Team, 2018. R: A language and environment for statistical computing. R Foundation for Statistical Computing, Vienna.

Reid, A. J., A. K. Carlson, I. F. Creed, E. J. Eliason, P. A. Gell, P. T. J. Johnson, K. A. Kidd, T. J. MacCormack, J. D. Olden, S. J. Ormerod, J. P. Smol, W. W. Taylor, K. Tockner, J. C. Vermaire, D. Dudgeon \& S. J. Cooke, 2019. Emerging threats and persistent conservation challenges for freshwater biodiversity. Biological Reviews 94: 849-873.

Rogger, M., M. Agnoletti, A. Alaoui, J. C. Bathurst, G. Bodner, M. Borga, V. Chaplot, F. Gallart, G. Glatzel, J. Hall, J. Holden, L. Holko, R. Horn, A. Kiss, S. Kohnová, G. Leitinger, B. Lennartz, J. Parajka, R. Perdigão, S. Peth, L. Plavcová, J. N. Quinton, M. Robinson, J. L. Salinas, A. Santoro, J. Szolgay, S. Tron, J. J. H. van den Akker, A.
Viglione \& G. Blöschl, 2017. Land use change impacts on floods at the catchment scale: challenges and opportunities for future research. Water Resources Research 53: 5209-5219.

Rolke, D., B. Jaenicke, J. Pfaender \& U. Rothe, 2018. Drainage ditches as important habitat for species diversity and rare species of aquatic beetles in agricultural landscapes (Insecta: Coleoptera). Journal of Limnology 77: 3.

Sánchez-Bayo, F., P. van der Brink \& R. M. Mann, 2011. Ecological impacts of toxic chemicals. Betham eBooks, Sharjah.

Shaw, R. F., P. J. Johnson, D. W. Macdonald \& R. E. Feber, 2015. Enhancing the biodiversity of ditches in intensively managed UK farmland. PLoS ONE 10: e0138306.

Silva, E., M. A. Daam \& M. J. Cerejeira, 2015. Predicting the aquatic risk of realistic pesticide mixtures to species assemblages in Portuguese river basins. Journal of Environmental Sciences 31: 12-20.

Skempton, A. W., 1998. The engineering works of John Grundy (1719-1783). In Ciriacono, S. (ed), Land drainage and irrigation. CRC Press, London: 191-230.

South Lincolnshire Fenlands Partnership, 2019. Re-creating lost wild fenlands. http://www.lincsfenlands.org.uk/.

Thaler, T. \& M. Levin-Keitel, 2016. Multi-level stakeholder engagement in flood risk management: a question of roles and power: Lessons from England. Environmental Science and Policy 55: 291-301.

Verdonschot, R. C. M., H. E. Keizer-vlek \& P. F. M. Verdonschot, 2011. Biodiversity value of agricultural drainage ditches: a comparative analysis of the aquatic invertebrate fauna of ditches and small lakes. Aquatic Conservation: Marine and Freshwater Ecosystems 21: 715-727.

Verdonschot, R. C. M., H. E. Keizer-Vlek \& P. F. M. Verdonschot, 2012. Development of a multimetric index based on macroinvertebrates for drainage ditch networks in agricultural areas. Ecological Indicators 13: 232-242.

Williams, P., M. Whitfield, J. Biggs, S. Bray, G. Fox, P. Nicolet \& D. A. Sear, 2003. Comparative biodiversity of rivers, streams, ditches and ponds in an agricultural landscape in Southern England. Biological Conservation 115: 329-341.

Publisher's Note Springer Nature remains neutral with regard to jurisdictional claims in published maps and institutional affiliations. 